\title{
First Fabulous Fifty - An Initial Experience of Dulaglutide from a Tertiary Care Centre in Eastern India
}

\author{
Soumyabrata Roy Chaudhuri ${ }^{1 *}$, Anirban Majumder ${ }^{2}$ and Debmalya Sanyal ${ }^{2}$ \\ ${ }^{1}$ Senior Registrar, Department of Endocrinology KPC Medical College \& Hospital, Kolkata, India \\ ${ }^{2}$ Professor, Department of Endocrinology, KPC Medical College \& Hospital, Kolkata, India
}

${ }^{\star}$ Corresponding Author: Soumyabrata Roy Chaudhuri, Senior Registrar, KPC Medical College \& Hospital, 1F, Raja SC Mullick Road, Jadavpur, Kolkata-700032, West Bengal, India; Tel: 09830047301; E-mail: soumya.academics@gmail.com

Received: September 10, 2018; Accepted: October 26, 2018; Published: November 22, 2018;

\begin{abstract}
Objective: This retrospective single centred real world observational study was undertaken with the aim to introspect the glycaemic control, weight loss, changes in lipid parameters, adverse events and treatment adherence with Dulaglutide therapy.

Methodology: Single centered, retrospective, real world, observational study conducted on subjects taking liraglutide for a mean duration of 41 weeks in the endocrine out-patient department.

Results: Data of 45 subjects were available. Mean age was $46.67 \pm 5.53$ years. Glycosylated haemoglobin (HbA1c) significantly decreased from $8.68 \pm$ $0.43 \%$ at baseline to $7.58 \pm 0.19 \%$ at end of therapy. Body weight significantly reduced from $74.2 \pm 8.07 \mathrm{~kg}$ at baseline to $69.27 \pm 4.74 \mathrm{~kg}$ at end of therapy and BMI significantly declined from $33.06 \pm 4.5$ to $30.09 \pm 0.93$ at end of therapy respectively. Nausea, vomiting and diarrhoea (15.55\%) were the major adverse events noted in the study. Only one patient developed acute pancreatitis $(2.22 \%)$.

Conclusion: Treatment with Dulaglutide resulted in clinically meaningful HbA1c, FPG and weight reductions. The overall safety profile is consistent with the GLP-1 receptor agonist class. However, Dulaglutide did not show statistically greater reduction of glycaemic parameters in the subset of Indian patients compared to RCT data of Western population.
\end{abstract}

Keywords: Dulaglutide, obesity, Indian, type 2 diabetes

\section{Introduction}

Glucagon-like peptide-1 (GLP-1) agonists act at GLP-1 receptors in pancreatic beta cells to increase glucose-dependent insulin secretion, in pancreatic alpha cells to decrease glucagon release and slow gastric emptying. Over the years, glucagon-like peptide-1 receptor agonists (GLP-1 RAs) have become integral in diabetes management as demonstrated by various publications from India [1-7]. Short-acting GLP-1 RAs requires either a once-daily (e.g. liraglutide) or twice-daily dosing (e.g., exenatide and lixisenatide). Studies published as back as 2005 from India by Vijan et. Al [8]. Showed that the injection burden was definitely an issue to be considered. When adherence to injectable treatment was looked into, the increased number of injection burden was found to be responsible for missed doses and non-adherence to treatment (GAAP study) [9]. Dulaglutide is longer acting GLP-1RA for the treatment of type 2 diabetes mellitus (T2D) and requires onceweekly dosing [10]. Hence the launch of Dulaglutide since march 2016 in India, the novel once weekly GLP1 RA was an welcome step and expected to increase the adherence to GLP1 RA treatment. However, adverse effects if any with one shot of the weekly once Dulaglutide would carry on for the entire week relentlessly. This retrospective single centred real world observational study was undertaken with the aim to introspect the glycaemic control, weight loss, changes in lipid parameters, adverse events and treatment adherence with Dulaglutide therapy.

\section{Materials and Methods}

This retrospective real world observational study was conducted in the Endocrinology Department of KPC Medical College and Hospital. It is a 700 bedded tertiary care hospital, situated in the southern fringes of the city of Kolkata, in the eastern part of India. The Endocrine outpatient database was frisked to tease out the initial 50 patients who were prescribed Dulaglutide over and above standard of care (with the exception that DPP 4 inhibitors if any on board) and weren't lost to follow-up thereafter irrespective of the fact whether they were able to initiate or carry on Dulaglutide therapy continuously or not. No patients with e GFR $<30$, family history of medullary carcinoma of the thyroid and history of pancreatitis were offered the Dulaglutide as a standard of care of the Department.

The inclusion and exclusion criteria used while selecting the cohort of patients were as follows:

\section{Inclusion Criteria:}

1. Adult type 2 diabetes between $18-75$ year age

2. $\mathrm{HbA} 1 \mathrm{C}>=7 \%$ and $<11 \%$ on a combination of $\mathrm{OAD} \pm$ insulin 
3. First 50 patients to be prescribed Dulaglutide therapy and who came for a second follow up irrespective of whether he/she had started Dulaglutide.

\section{Exclusion Criteria:}

1. Patients who were initially prescribed Dulaglutide but were lost to follow up after $1^{\text {st }}$ visit

2. Pregnancy

3. Hospitalisation during follow-up

\section{Statistical Analysis}

Descriptive statistical analysis has been carried out in the present study. Results on continuous measurements are presented on Mean \pm SEM and results on categorical measurements are presented in Number (\%). Significance is assessed at a level of $5 \%$.

The following assumptions on data are made.

\section{Assumptions:}

1. Cases of the samples should be independent.

2. The populations from which the samples are drawn have the same variance (or standard deviation).

3. The samples drawn from different populations are random.

Normality of data tested by Anderson Darling test, Shapiro-Wilk, Kolmogorov-Smirnoff test and visually by QQ plot. Paired t-test has been used to find the significance of study parameters within groups of patients measured on two occasions.

Statistical software: The Statistical software namely SAS (Statistical Analysis System) version 9.2 for windows, SAS Institute Inc. Cary, NC, USA and Statistical Package for Social Sciences (SPSS Complex Samples) Version 21.0 for windows, SPSS, Inc., Chicago, IL, USA were used for the analysis of the data and Microsoft word and Excel have been used to generate graphs and tables.

\section{Results and Analysis}

In the present analyses, a total of 50 patients with T2D were included out of which 45 did actually initiate the drug as was revealed in the first follow-up visit. Patient numbers for gender, age, height, BMI, duration of diabetes, baseline blood pressure, FPG, PPPG, HbA1c, Cholesterol, HDL, LDL, TG and duration of follow up are listed in Table 1. Out of 45, 24 were female and 21 were male having a mean age of $46.67 \pm 5.53$ years. The patients had a mean height, mean body weight of $74.2 \pm 8.07 \mathrm{~kg}$ and mean BMI of $33.06 \pm 1.47$ $\mathrm{kg} / \mathrm{m}^{2}$. The mean FPG was $169.18 \pm 11.38 \mathrm{mg} / \mathrm{dl}$, PPPG was $222.46 \pm$ $23.77 \mathrm{mg} / \mathrm{dl}$ and mean Hbalc was $8.68+-0.43 \%$ before the initiation of Dulaglutide. The baseline demographic and clinical characteristics of the study subjects are enumerated in (Table 1). Post analysis it was revealed that the mean follow up period for the 45 patients who ultimately initiated dulaglutide therapy was $41.2 \pm 11.71$ weeks.

\section{HbAlc, FBG reductions and weight changes}

All the glycaemic parameters viz. FPG, PPPG and HbA1C had statistically significant reductions, with the respective $p$ values achieved being $0.044,0.018$ and 0.032 during the study period. FPG was reduced by $31.14 \pm 0.17 \mathrm{mg} / \mathrm{dl}$, PPPG was reduced by $53.02 \pm$ $10.52 \mathrm{mg} / \mathrm{dl}$ and HBA1C was also reduced by $1.10 \pm 0.24 \%$. (Table 2 ) In this small subgroup of patients $22.2 \%$ achieved a target HBA1C of less than $7 \%$ and $55.56 \%$ achieved a target of less than $7.5 \%$, which is a significant proportion considering the fact that the average HBA1C of Indian Diabetic patients undergoing treatment is far higher than this (18). $26.67 \%$ of patients were able to achieve a reduction of greater than $1 \%$ HBA1C , $17.78 \%$ achieved a reduction between $0.5 \%-1.0 \%$, however interesting is the fact that $37.78 \%$ showed no change in HBA1C and $13.33 \%$ were showing an increased HBA1C than that at baseline (Table 3, 4).

Table 1. Baseline Characteristics of the Patients $(\mathrm{N}=45)$

\begin{tabular}{|c|c|}
\hline Demographic \& Clinical Profile & Values \\
\hline Male, n (\%) & $21(46.67)$ \\
\hline Female, n (\%) & $24(53.33)$ \\
\hline Age(years), Mean \pm SEM & $46.67 \pm 5.53$ \\
\hline Height (centimeters), Mean \pm SEM & $161.63 \pm 11.42$ \\
\hline Body weight $(\mathrm{Kg})$, Mean \pm SEM & $74.2 \pm 8.07$ \\
\hline $\mathrm{SBP}(\mathrm{mmHg})$, Mean \pm SEM & $133.68 \pm 12.11$ \\
\hline $\mathrm{DBP}(\mathrm{mmHg})$, Mean \pm SEM & $84.03 \pm 10.51$ \\
\hline BMI $\left(\mathrm{kg} / \mathrm{m}^{2}\right)$, Mean \pm SEM & $33.06 \pm 1.47$ \\
\hline BMI - $23-29.9$ & $22(48.89 \%)$ \\
\hline BMI - 30-34.9 & $11(24.44 \%)$ \\
\hline BMI - 35-39.9 & $11(24.44 \%)$ \\
\hline BMI - $\geq 40$ & $1(2.22 \%)$ \\
\hline $\mathrm{FPG}(\mathrm{mg} / \mathrm{dL})$, Mean \pm SEM & $169.18 \pm 11.38$ \\
\hline PPPG $(\mathrm{mg} / \mathrm{dL})$, Mean $\pm \mathrm{SEM}$ & $222.46 \pm 23.77$ \\
\hline HbAlc $(\%)$, Mean \pm SEM & $8.68 \pm 0.43$ \\
\hline Total Cholesterol (mg/dL), Mean \pm SEM & $165.68 \pm 6.23$ \\
\hline LDL- Cholesterol (mg/dL), Mean \pm SEM & $115.06 \pm 27.2$ \\
\hline HDL- Cholesterol (mg/dL), Mean \pm SEM & $42.35 \pm 1.70$ \\
\hline Triglycerides $(\mathrm{mg} / \mathrm{dL})$, Mean \pm SEM & $189.87 \pm 12.35$ \\
\hline Duration of follow-up (weeks), Mean \pm SEM & $41.2 \pm 11.71$ \\
\hline
\end{tabular}

Table 2. Change in study parameters during the follow-up period, $(\mathrm{N}=45)^{* *}$

\begin{tabular}{|l|c|c|c|}
\hline \multicolumn{1}{|c|}{ Parameter } & $\begin{array}{c}\text { Baseline } \\
\text { Mean } \pm \text { SEM }\end{array}$ & $\begin{array}{c}\text { Follow-up** } \\
\text { Mean } \pm \text { SEM }\end{array}$ & P value \\
\hline Body weight $(\mathrm{kg})$ & $74.2 \pm 8.07$ & $69.27 \pm 4.74$ & $<0.001$ \\
\hline $\mathrm{BMI}\left(\mathrm{kg} / \mathrm{m}^{2}\right)$ & $33.06 \pm 1.47$ & $30.09 \pm 0.93$ & 0.041 \\
\hline $\mathrm{SBP}(\mathrm{mmHg})$ & $133.68 \pm 12.11$ & $130.92 \pm 3.63$ & 0.731 \\
\hline $\mathrm{DBP}(\mathrm{mmHg}$ & $84.03 \pm 10.51$ & $81.65 \pm 8.03$ & 0.930 \\
\hline $\mathrm{FPG}(\mathrm{mg} / \mathrm{dl})$ & $169.18 \pm 11.38$ & $138.04 \pm 11.21$ & 0.044 \\
\hline $\mathrm{PPPG}(\mathrm{mg} / \mathrm{dl})$ & $222.46 \pm 23.77$ & $169.44 \pm 13.25$ & 0.018 \\
\hline
\end{tabular}




\begin{tabular}{|l|c|c|c|}
\hline \multicolumn{1}{|c|}{ Parameter } & $\begin{array}{c}\text { Baseline } \\
\text { Mean } \pm \text { SEM }\end{array}$ & $\begin{array}{c}\text { Follow-up** } \\
\text { Mean } \pm \text { SEM }\end{array}$ & P value \\
\hline HbA1c $(\%)$ & $8.68 \pm 0.43$ & $7.58 \pm 0.19$ & 0.032 \\
\hline Total Cholesterol (mg/dL) & $165.68 \pm 6.23$ & $142.11 \pm 6.17$ & 0.020 \\
\hline LDL- Cholesterol (mg/dL) & $115.06 \pm 27.2$ & $71.95 \pm 5.57$ & 0.43 \\
\hline HDL- Cholesterol (mg/dL) & $42.35 \pm 1.70$ & $42.26 \pm 3.15$ & 0.178 \\
\hline Triglycerides (mg/dL) & $189.87 \pm 12.35$ & $137.21 \pm 10.05$ & 0.068 \\
\hline $\begin{array}{l}\mathrm{p}<0.05 \text { considered as statistically significant, p computed by paired-t-test, } \\
\text { ** Calculated as per the data available at last follow-up visit }\end{array}$ \\
\hline
\end{tabular}

Table 3. Proportion of patients achieving HbAlc less than 7\%, 7\%-7.5\%, 7.5\%-8.5\% and beyond, $(\mathrm{N}=45)$

\begin{tabular}{|c|c|c|}
\hline Follow-up HbA1c (in \%) & Number of subjects & \% of subjects \\
\hline$<7 \%$ & 8 & 17.78 \\
\hline $7 \%-7.5 \%$ & 10 & 22.22 \\
\hline $7.5-8.5 \%$ & 8 & 17.78 \\
\hline$>8.5 \%$ & 2 & 4.44 \\
\hline Drop-out & 17 & 37.78 \\
\hline
\end{tabular}

Table 4. Change in HbAlc from baseline to follow-up, $(\mathrm{N}=45)$

\begin{tabular}{|l|c|c|}
\hline Change in HbA1c (in \%) & Number of subjects & \% of subjects \\
\hline Drop of $1 \%$ and more & 12 & 26.67 \\
\hline Drop of $0.5 \%$ to $1 \%$ & 8 & 17.78 \\
\hline Drop of less than $0.5 \%$ & 2 & 4.44 \\
\hline Increase from baseline & 6 & 13.33 \\
\hline Drop out at 3 months & 17 & 37.78 \\
\hline
\end{tabular}

The statistical analysis of the cohort of 45 patients revealed a weight loss of $4.93 \pm 3.33 \mathrm{~kg}$ which had a $\mathrm{p}$ value of $<0.001$ and thereby also achieved a statistically significant reduction in BMI from an initial value of $33.06 \pm 1.47 \mathrm{~kg} / \mathrm{m}^{2}$ to $30.09 \pm 0.93 \mathrm{~kg} / \mathrm{m}^{2}$ ( $\mathrm{p}$ value 0.041). (Table 2) Weight benefits were more robust with $40 \%$ showing a weight loss of $5 \%$ or less from the baseline and another $20 \%$ showing a weight loss between $5.1-10 \%$ from the baseline. 3 patients who had Insulin and Pioglitazone on board showed an increase in weight from the baseline and as many as $28.87 \%$ of patient showed no appreciable change in bodyweight despite addition of Dulaglutide reiterating the presence of non-responders to GLP 1 RA therapy with respect to reduction of weight (Table 5).

Table 5. Percentage Change in Weight during the 3 months follow-up period, $(\mathrm{N}=45)$

\begin{tabular}{|l|c|c|}
\hline & Number of subjects & \% of subjects \\
\hline Weight gain & 3 & 6.67 \\
\hline Weight loss (Less than 5\%) & 14 & 31.11 \\
\hline Weight loss (5.1\% to 10\%) & 9 & 20 \\
\hline $\begin{array}{l}\text { Weight loss } \\
\text { (Greater than } 10 \%)\end{array}$ & 2 & 4.44 \\
\hline Drop out & 17 & 28.89 \\
\hline
\end{tabular}

\section{Blood pressure and lipid changes}

When the blood pressure and lipid data of the 45 patients were analysed, systolic and diastolic pressure did not show any statistically significant reduction and amidst the lipid parameters only the total cholesterol values showed a significant reduction with a $\mathrm{p}$ value of 0.20 (Table 2).

\section{Hypoglycaemia Gastrointestinal adverse events}

Nausea, vomiting and diarrhoea (15.55\%) were the major adverse events noted in the study. Only one patient developed acute pancreatitis (2.22\%). Ten patients $(22.22 \%)$ had to discontinue Dulaglutide due to financial constraints. (Table 6,7)

Table 6. Reason for Drop-out

\begin{tabular}{|l|c|c|}
\hline Reason for Drop-out & Number of subjects & \% of subjects \\
\hline Financial constraint & 10 & 22.22 \\
\hline Nausea/Vomiting & 6 & 13.33 \\
\hline Acute Pancreatitis & 1 & 2.22 \\
\hline Diarrhea & 1 & 2.22 \\
\hline
\end{tabular}

Table 7. Adverse Effect Profile

\begin{tabular}{|l|c|c|}
\hline Reason for Drop-out & Number of subjects & \% of subjects \\
\hline Nausea/Vomiting & 6 & 13.33 \\
\hline Acute Pancreatitis & 1 & 2.22 \\
\hline Diarrhea & 1 & 2.22 \\
\hline
\end{tabular}

\section{Discussion}

In this analysis of the 45 patients who (out of the 50 patients prescribed) we observed significant reduction of $\mathrm{HbAlc}$ with the initiation of Dulaglutide which was similar in either sex and as expected with all anti diabetic agents the fall was greater in the group with a higher baseline $\mathrm{HbA1c}(8.5 \%$ and above) and the drop of HbA1c achieved was $1.1 \pm 0.24 \%$. Fasting plasma glucose was reduced by $31.14 \pm 0.14 \mathrm{mg} / \mathrm{dl}$ and the post prandial values dropped by $53.02 \pm 10.52 \mathrm{mg} / \mathrm{dl}$ at the end of the analysis period. The change in the glycaemic indices namely HbA1c, FPG and PPPG all achieved statistical significance with $p$ values of $0.032,0.044$ and 0.018 respectively.

Amidst the other parameters measured and the lipid parameters did not achieve statistical significance - except for the total cholesterol value which showed a drop of $23.57 \pm 0.06 \mathrm{mg} / \mathrm{dl}$ and had a $\mathrm{p}$ value of 0.020 which was statistically significant. Weight however showed an overwhelming drop of $4.93 \pm 3.33 \mathrm{~kg}$ and BMI also showed a drop of $2.97 \pm 0.54 \mathrm{~kg} / \mathrm{m}^{2}$-both thus achieving statistical significance with $\mathrm{p}$ values of $<0.001$ and 0.041 . When we compare this data with the data of the various AWARD trials some stark differences do stand out all of which can perhaps be explained and some of which can be expected as a part of standard differences which occur in between RCTs and RWE (real world evidence) generated data. Dulaglutide being an once weekly GLP-1RAs is structurally a large molecule and is expected to have a more profound action over fasting plasma glucose 
rather than on the post prandial plasma glucose levels [11], however in this real world generated data the same was not reflected due to the heterogeneity of concomitant anti diabetic medication which perhaps played a differential role in the control of fasting and post prandial blood glucose levels. AWARD 3 assessed dulaglutide monotherapy at $1.5 \mathrm{gm}$ dose over a 52 week period and achieved an $\mathrm{HbAlC}$ reduction of $0.78 \pm 0.06 \%$ and this data from the series of AWARD studies was less than the $\mathrm{HbA} 1 \mathrm{c}$ reduction achieved in the subset of patients which we included in our study cohort [12]. AWARD 2 studied the effect of Dulaglutide on top of existing glimepiride and metformin therapy and over a period of 72 weeks and the $\mathrm{HbAlc}$ reduction of $1.08 \pm 0.06$ achieved, was a wee bit less than that achieved in our subjects; who, however had a mean duration of follow up of just over 41 weeks [13]. AWARD 1 studied Dulaglutide $1.5 \mathrm{mg}$ in addition to Pioglitazone (30- $45 \mathrm{mg}$ ) and Metformin (2000- 3000mg) over a period of 24 weeks and showed a robust reduction of $\mathrm{HbAlc}$ of $-1.51 \pm 0.06$ which was substantially greater than that achieved in our real world study of just over 41 weeks [14]. This discrepancy between the two reductions achieved may be attributed to the fact that both Pioglitazone and Metformin were used in lower doses of 7.5-15 mg and 1500-2000 mg respectively. AWARD-4 [15] studied prandial doses of insulin Lispro in addition to Dulaglutide over a period of 26 weeks and the combination achieved the highest HbA1c reduction of $-1.64 \%(95 \%$ CI -1.50 to - 1.78) and AWARD-10 studied effect of Dulaglutide 1.5 $\mathrm{mg}$ and SGLT2 inhibitor combination over a similar time period and achieved a HbAlc reduction of $1.34 \%$ [16]. The HbAlc reductions in these two RCTs were however significantly more than that achieved in our real world data of just over 41 weeks of Dulaglutide therapy.

In general, Incretin based therapies are more efficacious in the south-east Asian population suffering from Type 2 Diabetes than in their counterparts coming from the Western world [17]. With the previously available once daily GLP1RA - Liraglutide; the Indian experience (1-7) when taken together also showed superior glycaemic control and weight reduction than all the LEAD trials [18] which were RCTs performed with the same drug in Western population used at a dose of $1.8 \mathrm{mg} /$ day - a dose which was not always used in the Indian real world studies. Doses as low as $0.6 \mathrm{mg} /$ day were used and $1.2 \mathrm{mg} /$ day rather than $1.8 \mathrm{mg} /$ day was the most frequently used dosage) [19].

The weight loss achieved by the subjects in this real world study is quite robust - a loss of $4.93 \pm 3.33 \mathrm{~kg}$. Considering the impact of weight loss on remission of diabetes as shown in the DIRECT trial [20] published in The Lancet, this weight loss, if it can be sustained over longer periods may have substantial role to play in redirecting the future management of diabetes in these subjects. If we closely assess the data 15 out of 50 subjects were not able to carry on Dulaglutide and dropped out on economic grounds. Of these, five patients came back to state that although prescribed reconsidering their finances they were unable to start the drug. Of the rest, ten more patients dropped out within the observation period, cumulating to a drop-out rate of $30 \%$ within the first year. GLP-1 RAs usually are thought to exert their cardiovascular benefit via modification of the atherosclerotic pathway [21] due to the delayed bifurcation of the outcomes graph in contrast to that of SGLT2 inhibitors [22]. Thus choosing the right patient who can carry on the GLP-1 therapy for longer periods to harness the
CV outcome benefits also should be a clinical consideration before initiating the therapy.

\section{GI Side effect and Drop-out}

The incidence of gastrointestinal adverse events on dulaglutide treatment was observed in $41.47 \%$ of patient's. Out of 45 subjects, 18 had stopped treatment. Limitations in these analyses restrict the application of these data to the larger population of patients with T2D. No placebo or active comparator data were included in the analyses. The number of patients was small and may not necessarily be representative of the entire T2D patient population in clinical practice. The mean duration of diabetes of years and the mean age of 46 years were typical for the real world study, but may differ from the wider T2D population. Moreover, the durations of the study in the present analysis were limited to 32.2 weeks, which may not reflect the effect of longer-term use of dulaglutide.

\section{Conclusion}

Treatment with dulaglutide resulted in clinically meaningful HbAlc, FBG and weight reductions. The overall safety profile is consistent with the GLP-1 receptor agonist class. However, Dulaglutide did not show statistically greater reduction of glycaemic parameters in the subset of Indian patients compared to RCT data of Western population.

\section{References}

1. Kaur P, Mahendru S, Mithal A (2016) Long-term efficacy of liraglutide in Indian patients with Type 2 diabetes in a real-world setting. Indian J Endocrinol Metab 20: 595-599. [crossref]

2. Kaur P, Mishra SK, Mittal A, Saxena M, Makkar A, et al. (2014) Clinical experience with Liraglutide in 196 patients with type 2 diabetes from a tertiary care center in India. Indian J Endocrinol Metab 18: 77-82.

3. Kesavadev J, Shankar A, Gopalakrishnan G, Jothydev S (2015) Efficacy and safety of liraglutide therapy in 195 Indian patients with type 2 diabetes in real world setting. Diabetes MetabSyndr 9: 30-33.

4. Roy Chaudhuri S, Sanyal D, Majumder A, Bhattacharjee K (2016) LIRA 365 Plus-A Real World Experience of 82 week Use of Liraglutide in the Obese Indian Type 2 Diabetic Subjects. AdvObes Weight Manag Control 5: 00136.

5. Roy Chaudhuri S, Sanyal D, Majumder A, Bhattacharjee K (2016) Short Term Outcomes of Low Dose Liraglutide in Obese Non Diabetic Indian Subjects-A Real World Experience. Diabetes ObesInt J 1: 000140.

6. Sanyal D, Majumdar A (2013) Low dose liraglutide in Indian patients with type 2 diabetes in the real world setting. Indian J Endocrinol Metab 17: 301-303. [crossref]

7. Majumder Anirban, Bhattacharjee K (2017) Beginning With Very Low Dose $(0.2 \mathrm{mg})$ Liraglutide in Indian Type 2 Diabetic Patients Appears Better Tolerated: Experience from Real Life Practice. J Diabetes MetabDisord Control 4: 00127.

8. Vijan S, Hayward RA, Ronis DL (2005) The Burden of Diabetes Therapy: Implications for the Design of Effective Patient-centered Treatment Regimens. $J$ Gen Int Med 20: 479-482.

9. Peyrot M, Barnett AH, Meneghini LF, Schumm-Draeger P-M (2012) Insulin adherence behaviours and barriers in the multinational Global Attitudes of Patients and Physicians in Insulin Therapy study. Diabetic Medicine 29: 682-689.

10. Kalra S, Baruah MP, Sahay RK, Unnikrishnan AG, Uppal S, et al. (2016) Glucagonlike peptide-1 receptor agonists in the treatment of type 2 diabetes: Past, present, and future. Indian Journal of Endocrinology and Metabolism 20: 254-267.

11. Miñambres I, Pérez A (2017) Is there a justification for classifying GLP-1 receptor agonists as basal and prandial? Diabetology \& Metabolic Syndrome 9: 1-6.

12. Umpierrez G, ToféPovedano S, Pérez Manghi F, Shurzinske L, Pechtner V (2014) Efficacy and safety of dulaglutide monotherapy versus metformin in type 2 diabetes in a randomized controlled trial (AWARD-3). Diabetes Care 37: 2168-2176.

13. Giorgino F, Benroubi M, Sun JH, Zimmermann AG, Pechtner V (2015) Efficacy and Safety of Once-Weekly Dulaglutide Versus Insulin Glargine in Patients With Type 2 Diabetes on Metformin and Glimepiride (AWARD-2). Diabetes Care 38: 2241-2249 
14. Wysham C, Blevins T, Arakaki R, Colon G, Garcia P, et al. (2014) Efficacy and Safety of Dulaglutide Added Onto Pioglitazone and Metformin Versus Exenatide in Type 2 Diabetes in a Randomized Controlled Trial (AWARD-1). Diabetes Care 37: $2159-2167$.

15. Blonde L, Jendle J, Gross J, Woo V, Jiang H, et al. (2015) Once-weekly dulaglutide versus bedtime insulin glargine, both in combination with prandial insulin lispro, in patients with type 2 diabetes (AWARD-4): a randomised, open-label, phase 3, noninferiority study. Lancet 385: 2057-2066.

16. Ludvik B, Frías JP, Tinahones FJ, Wainstein J, Jiang H, et al. (2018) Dulaglutide as add-on therapy to SGLT2 inhibitors in patients with inadequately controlled type 2 diabetes (AWARD-10): a 24-week, randomised, double-blind, placebo-controlled trial. Lancet Diabetes Endocrinol 6: 370-381.

17. Wong MCS, Wang HHX, Kwan MWM (2014) Comparative Effectiveness of Dipeptidyl Peptidase-4 (DPP-4) Inhibitors and Human Glucagon-Like Peptide-1 (GLP-1) Analogue as Add-On Therapies to Sulphonylurea among Diabetes Patients in the Asia-Pacific Region: A Systematic Review. Blachier F, ed. PLoS ONE 9: 90963.
18. Rigato M, Fadini GP (2014) Comparative effectiveness of liraglutide in the treatment of type 2 diabetes. Diabetes, Metabolic Syndrome and Obesity. Targets and Therapy 7: 107-120.

19. Sanyal D, Majumdar A (2013) Low dose liraglutide in Indian patients with type 2 diabetes in the real world setting. Indian J Endocrinol Metab 17: S301-303. [crossref]

20. Lean ME, Leslie WS, Barnes AC, Brosnahan N, Thom G, et al. (2018) Primary care-led weight management for remission of type 2 diabetes (DiRECT): an openlabel, cluster-randomised trial. Lancet 391: 541-551. [crossref]

21. Álvarez-Villalobos NA, Treviño-Alvarez AM, González-González JG (2016) Liraglutide and Cardiovascular Outcomes in Type 2 Diabetes. N Engl J Med 375: 1797-1798. [crossref]

22. Rosenstein R, Hough A (2016) Empagliflozin, Cardiovascular Outcomes, and Mortality in Type 2 Diabetes. N Engl J Med 374: 1093-1094. [crossref]

\section{Citation:}

Soumyabrata Roy Chaudhuri, Anirban Majumder and Debmalya Sanyal (2018) First Fabulous Fifty - An Initial Experience of Dulaglutide from a Tertiary Care Centre in Eastern India. Endocrinol Diabetes Metab $J$ Volume 2(4): 1-5 